\title{
Fat Aversion in Eating Disorders
}

\author{
ADAM DREWNOWSKI \\ The University of Michigan
}

BEVERLY PIERCE and KATHERINE A. HALMI
Department of Psychiatry, Cornell University Medical College

\begin{abstract}
Patients with eating disorders are reported to show an irrational dislike of starchy foods, sometimes described as a "carbohydrate phobia". In the present study, foodrelated attitudes and self-reported food preferences of women patients with anorexia nervosa $(N=13)$, anorexia with bulimia $(N=16)$ and bulimia $(N=14)$ were mapped using multidimensional scaling (MDS) procedures and compared to those of normal-weight controls $(N=49)$. Sixteen common food names were rated along 9-point category scales for their nutritional similarity, perceived macronutrient content, caloric density and overall nutritional value. MDS (SINDSCAL) and property fitting (PROFIT) procedures revealed that eating disorder patients associated calories with fat content to a grcater extent than did controls, and tended to dislike high-fat foods. In contrast, no differences in perceptions or preferences for carbohydrate foods were observed. Anorectic restrictor patients showed the most rigid attitude structure, expressing preferences only for the lowest calorie and the most nutritious foods. The present multivariate techniques of mapping perceptual space may help to distinguish between diagnostic subgroups in studies of eating disorders.
\end{abstract}

\section{INTRODUCTION}

The psychiatric diagnosis of eating disorders distinguishes between anorexia and bulimia nervosa (American Psychiatric Association, 1987). Anorexia nervosa is characterized by extreme dietary restriction and a severe loss of body weight. Bulimia involves frequent binge-eating episodes, often followed by fasting, purging, or selfinduced vomiting. More than half of anorectic patients show symptoms of bulimia, alternating binges and purges with periods of fasting or rigorous dieting (Casper $e t$ al., 1980).

The pattern of food avoidance by anorectic women has been described as a "carbohydrate phobia" (Crisp \& Kalucy, 1974). Anorectic restrictor patients are said to show signs of "carbohydrate starvation" (Crisp, 1965) and their carbohydrate intake has been reported to be low or non-existent (Hurst et al., 1977). Such patients profess revulsion for all fattening foods, studiously avoiding starches, sweets and desserts (Russell, 1967; Rosen et al., 1986). The typical diet of anorectic patients has been reported as low in carbohydrate but adequate in both protein and fat (Russell, 1967).

Supported by NIH Grants DK37011, DK38073 to A.D. and MH00516 and funds from General Foods Corp. to K.A.H.

We wish to thank David Homa for assistance with data analyses.

Requests for reprints should be addressed to: Adam Drewnowski, School of Public Health M-5164. The University of Michigan, Ann Arbor, MI 48109, U.S.A. 
However, strict avoidance of sweets and starches is not a stable trait of eating disorders. Binge-eating episodes in anorexia nervosa and bulimia tend to include such foods as pies, cake, ice cream and chocolate candy (Abraham \& Beumont, 1982; Mitchell \& Laine, 1985). Patients typically describe these as "bad" or "fattening" foods that they do not allow themselves to eat at other times (Abraham \& Beumont, 1982). Food binges are followed by guilt, depression and self-induced purging or vomiting to lose weight (Mitchell \& Laine, 1985).

Previous reports of a "carbohydrate phobia" have counted ice cream, pastries and other sweet desserts among the carbohydrate-rich foods (Russell, 1979). However many such foods arc in fact combinations of sugar and fat (Drcwnowski, 1987). Ice cream and chocolate often derive more calories from fat than from carbohydrate, as do many other binge foods, including salted snacks, crackers and potato chips (Pennington \& Church, 1980). It may be that the seeming avoidance of starchy foods conceals an aversion to foods viewed as high-calorie-that is an aversion to foods rich in fat (Drewnowski et al., 1984). At least one intake study has reported that anorectic patients ate a normal amount of carbohydrate but significantly less fat than did normal weight controls (Beumont \& Chambers, 1981).

Attitudes towards food are reported to be a good predictor of food consumption (Shepherd \& Stockley, 1985). According to clinical reports, anorectic women often exhibit extreme and dichotomous thinking patterns, perceiving foods as either wholly "healthy" or "unhealthy" (Garner \& Garfinkel, 1985; Garner \& Bemis, 1982). Such women are thought to avoid starchy foods primarily because they regard them as unhealthy and fattening (Russell, 1979). Bulimic patients obsessively avoid forbidden binge-type "junk" foods (Garner et al., 1985; Logue et al., 1983), consuming them only if they plan in advance to vomit afterwards. Much therapeutic effort has gone into modifying the patients' extreme attitudes toward high-calorie foods, with nutritional counselling becoming an integral part of treatment programs (see e.g. Garner et al., 1985). However, although many clinicians have noted that eating disorder patients exhibit a variety of misconceptions about food and eating (Garner et al., 1985), there have been no systematic studies of nutrition-related attitudes and beliefs of patients with anorexia nervosa or bulimia.

The relationship between consumer attitudes, food preferences and food selection has been studied in a variety of market research contexts (Roering et al., 1986). One powerful method of creating perceptual maps involves a mathematical technique known as multidimensional scaling (MDS) (Drewnowski, 1982, 1985). MDS procedures transform sets of proximity judgments into a multidimensional map of stimulus points. Foods judged to be nutritionally similar are located close to one another in the resulting perceptual space, while foods viewed as dissimilar are located farther apart. The principal axes of such space usually reflect the chief perceptual dimensions of stimulus items, while the measure of subject weights reflects the salience of each dimension to each individual. Any tendency to divide foods into extreme and absolutist categories will be thus reflected in the form of an altered perceptual map as derived by MDS.

In the present study, MDS procedures were used to map the perceptual space of anorectic and bulimic patients and normal-weight controls. The subjects rated pairs of food names for nutritional similarity, and assessed each item for its perceived macronutrient content, caloric density, and overall nutritional value. The subjects also rated their liking for each food (the affective component of attitude) along 9-point hedonic preference scales. Both attribute evaluations and preference ratings were then 
expressed as vectors mapped onto multidimensional space using standard property fitting techniques (Drewnowski, 1985; Schiffman et al., 1981). The subjects' motivation to diet was assessed using the 10-item Restraint Questionnaire (Herman, 1978).

\section{METHODS}

\section{Subjects}

Forty-three female patients meeting DSM IIIR criteria for eating disorders participated in the study. This group included 13 cases with a diagnosis of anorexia nervosa characterized by exclusive dieting (A.N. Restrictor), 16 cases with a diagnosis of anorexia with bulimia (A.N. Bulimic), and 14 cases of bulimia (Bulimic) with or without a previous history of anorexia nervosa. With one exception, bulimic patients purged regularly prior to admission: only one was diagnosed as having bulimia without purging. The diagnoses of anorexia nervosa or bulimia were made by two psychiatrists independently following interviews with the patients and their family members. Concurrence of diagnosis was required before the patient was accepted into the treatment program and into the study.

The patients were hospitalized at the Eating Disorders Clinic, Westchester Division, Cornell Medical Center. The treatment program includes medical care, nutritional rehabilitation, group therapy, individual cognitive psychotherapy and family counselling. The patients were tested shortly following their hospital admissions. The protocols were approved by the Institutional Review Board and informed consent was obtained from all patients.

Normal-weight female volunteers $(N=49)$ of comparable age and socioeconomic status were recruited at two university campuses through posted announcements seeking subjects for a study of taste and food preferences. The subjects were free of eating disorders as determined by their responses to a previously published and revised Eating Disorders Questionnaire (Halmi et al., 1981). Their heights and weights were measured in the laboratory.

Subject data are summarized in Table 1. Anorectic restrictor patients (mean age $16 \cdot 1$ years) were younger than the other three groups. Because age of onset of anorexia

TABLE 1

Summary of subject characteristics

\begin{tabular}{|c|c|c|c|c|c|}
\hline & $N$ & $\begin{array}{c}\text { Age } \\
\text { (years) }\end{array}$ & $\begin{array}{l}\text { Weight } \\
\text { (kg) }\end{array}$ & $\underset{\left(w t / h t^{2}\right)}{\mathrm{BMI}}$ & $\begin{array}{l}\text { Restrain } \\
\text { score }\end{array}$ \\
\hline A.N. Restrictor & 13 & $\begin{array}{l}16 \cdot 1 \\
(0 \cdot 6)\end{array}$ & $\begin{array}{l}37 \cdot 9 \\
(0.9)\end{array}$ & $\begin{array}{l}14.9 \\
(0 \cdot 4)\end{array}$ & $\begin{array}{l}22 \cdot 0 \\
(1 \cdot 8)\end{array}$ \\
\hline A.N. Bulimic & 16 & $\begin{array}{l}20 \cdot 3 \\
(1 \cdot 0)\end{array}$ & $\begin{array}{l}43.9 \\
(1.5)\end{array}$ & $\begin{array}{l}16 \cdot 2 \\
(0 \cdot 5)\end{array}$ & $\begin{array}{l}23 \cdot 4 \\
(1 \cdot 1)\end{array}$ \\
\hline Bulimic & 14 & $\begin{array}{l}19 \cdot 7 \\
(1 \cdot 1)\end{array}$ & $\begin{array}{l}55 \cdot 0 \\
(1.6)\end{array}$ & $\begin{array}{l}21 \cdot 0 \\
(0 \cdot 4)\end{array}$ & $\begin{array}{l}26 \cdot 0 \\
(1 \cdot 3)\end{array}$ \\
\hline Control subjects & 49 & $\begin{array}{l}21 \cdot 0 \\
(0 \cdot 4)\end{array}$ & $\begin{array}{l}56 \cdot 7 \\
(0.8)\end{array}$ & $\begin{array}{l}21 \cdot 0 \\
(0 \cdot 2)\end{array}$ & $\begin{array}{l}17 \cdot 1 \\
(0 \cdot 9)\end{array}$ \\
\hline
\end{tabular}


is usually between 13-17 years, this group included some girls under the age of 15. A reference to pediatric growth charts from the National Center for Health Statistics (Hamill et al., 1979) showed that mean body weight of A.N. restrictors $(37.9 \mathrm{~kg})$ was below the first percentile for 16-year-old girls, representing an extreme degree of underweight. Mean body weight of A.N. bulimic patients $(43.9 \mathrm{~kg})$ was below the fifth percentile for 20-year-old women. In contrast, body weights of normal-weight bulimic and control subjects were close to the median value for the reference population. The subjects' body mass indices $\left(\mathrm{BMI}=\mathrm{kg} / \mathrm{m}^{2}\right.$ ) are also included in Table 1 . Body mass index in adults is independent of stature and is reasonably well correlated with body fatness, thus permitting a comparison across groups.

\section{Procedures}

All subjects were given printed questionnaires containing a standard set of instructions:

"On the following pages are the names of a variety of foods. They include ice cream, doughnuts, milk, bread, soft drinks, vegetables, cookies, macaroni, cake, potatoes, potato chips, candy, peanut butter, eggs, fruit and cereals.

These items are presented in pairs, one pair at a time. We would like you to judge how different from each other in nutritional value are the items in each pair. Please use a 9-point scale, where 1 stands for 'very similar' and 9 stands for 'very different'. For example, if you think that milk and ice cream are very similar, put down a 1 or a 2. If you think they are very different, put down an 8 or a 9 . Please use intermediate numbers for other judgments, and try to use the whole scale in making evaluations.

Please rate the protein, fat, carbohydrate, and calorie content of each type of food, and the overall nutritional value as you see them, using the 9-point scales provided. Then please rate your preferences for each type of food, again using 9point scales."

Food names, selected from a food frequency questionnaire (Drewnowski, 1985) varied widely in perceived nutritional value, including foods that might be reasonably perceived as "healthy" or as "unhealthy". The criteria for similarity scaling were not specified and were left to the subject's own judgment. MDS procedures permit the analysis of subjective perceptual space and the study of differences between subject groups. The present computer-generated list included all 120 pairwise combinations of the 16 food names $(n[n-1] / 2)$ in a randomized order. Attribute ratings were obtained as 9-point responses to adjectives, with each quality ranging from "absent" (0) to "extreme" (9) (Drewnowski, 1985). The standard 9-point hedonic preference categories were used for preference evaluations (Peryam \& Pilgrim, 1957). The subjects also completed the 10-item Dietary Restraint Questionnaire (Herman, 1978; Drewnowski et al., 1982) that examines past weight fluctuations and the degree of concern with dieting.

\section{Data Analyses}

Similarity matrices were analysed using multidimensional scaling (SINDSCAL) and hierarchical clustering (HICLUS) procedures (Drewnowski, 1985; Schiffman et al., 1981). The SINDSCAL program creates a multidimensional space of stimulus points whose chief axes correspond to the principal attributes of the scaled objects. In addition, SINDSCAL provides estimates of dimension salience (subject weights), which reflect the relative importance of each dimension to individual subjects. Subject weights on Dimensions I and II as well as their sum of squares were then compared for 
patients and controls and for each subgroup separately (Schiffman et al., 1981). Property fitting by multiple regression (PROFIT) was used to relate the principal axes of stimulus space to specific properties such as fat content or calories. In this procedure, ratings on attribute scales are regressed over the principal dimensions of the stimulus space to give optimum weights corresponding to each multiple correlation. These are expressed as direction cosines-that is, regression coefficients normalized so that their sum of squares equals 1.0 for every scale. The relationship between perceived nutritional value and other attribute vectors was examined further by correlating vector cosines along Dimension I, separately for eating disorder patients and for controls. HICLUS clustering analyses (Johnson, 1967) werc conducted to validate the MDS solution and to reduce 16 foods to a smaller number of food categories. These analyses made use of the diameter method available as part of the hierarchical clustering (HICLUS) procedure. All computer programs were obtained from Bell Laboratories (Drewnowski, 1985).

The Mann-Whitney U-test was used to compare values of vector cosines along Dimension I for eating disorder patients and volunteer controls. This non-parametric test was chosen since the dependent variable was not normally distributed.

The relationship between food preferences and other food attributes was examined using correlation analyses. Individual correlation coefficients between preference ratings, perceived calories, and the perceived fat, carbohydrate and protein content of the 16 food names were obtained separately for each subject. Differences between eating disorder patients and volunteer controls were then analyzed using the Student's $t$-test. Differences in stated food preferences were also analyzed by using the $t$-test.

\section{RESUlts}

\section{Multidimensional Scaling}

Multidimensional scaling of the stimulus space for 92 subjects revealed no difference in perceptual mapping between eating disorder patients and controls. The best two-dimensional SINDSCAL solution accounted for 56 per cent of the variance. Dimension weights for eating disorder patients and normal controls were not significantly different, suggesting that both groups shared the same stimulus space or perceptual map. As shown in Figure 1, the horizontal axis of the stimulus space appears to discriminate between healthy or nutritious foods (fruit, vegetables) and foods viewed as unhealthy (candy, soft drinks). The vertical axis appears to discriminate between such foods as potatoes and bread (bottom) and eggs and milk (top) perhaps on the basis of carbohydrate versus protein/fat content.

Superimposed on stimulus space of Figure 1 are attribute vectors reflecting perceived carbohydrate content of the 16 food items, as rated by individual subjects. Food stimuli are represented as points in the space, while individual attribute ratings are represented as vectors radiating from the origin. Each subject is represented by an arrow.

Individual differences in attribute profiles are reflected in changing orientation of "carbohydrate" vectors as determined by the property fitting (PROFIT) procedure. Figure 1 shows that most subjects correctly rated doughnuts, cookies and potato chips (bottom left quadrant) as higher in carbohydrate content than either milk or eggs (top right quadrant). As a result, individual attribute vectors (arrows) predominantly clustered in the two lower quadrants of the MDS solution. No differences in ratings of 


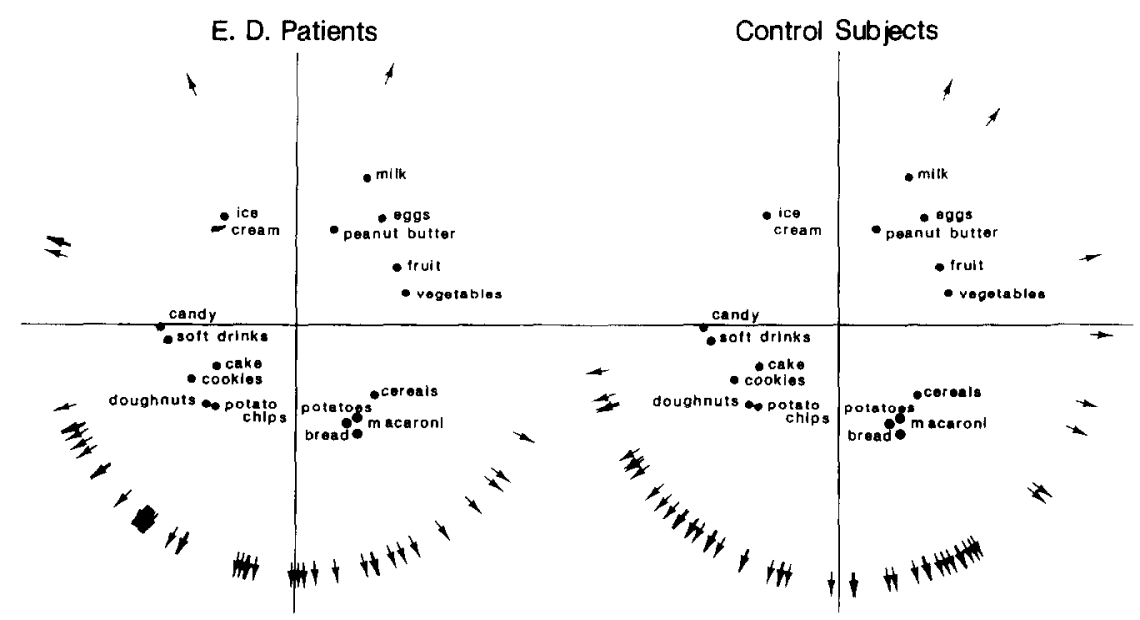

FIGURE 1. Plot of SINDSCAL stimulus space and individual attribute vectors reflecting ratings of carbohydrate content. Food stimuli are presented as points in space; directions of attribute vectors are represented as arrows from the origin. The data are shown separately for eating disorder patients and controls.

carbohydrate content were observed between eating disorder patients (or any diagnostic subgroup) and normal-weight controls (Mann-Whitney U-test).

Comparable results were obtained for individual assessments of fat content. Figure 2 shows that individual "fat" vectors were mostly found in the two left-hand quadrants of the MDS solution. No significant differences between control subjects and eating disorder patients were observed (Mann-Whitney U). Similarly, assessments of protein content (not shown) revealed no significant differences between eating disorder patients and controls.

All subjects agreed that fruit and vegetables were more nutritious than doughnuts, cookies or potato chips. Attribute vectors reflecting nutritional value were therefore

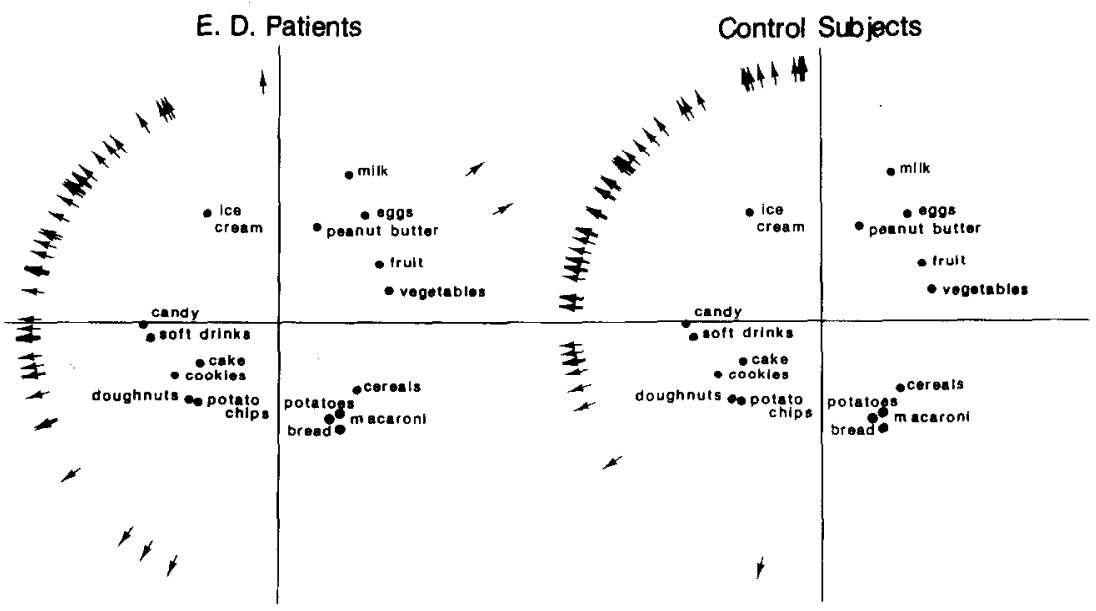

FIGURE 2. Plot of SINDSCAL stimulus space and individual attribute vectors reflecting ratings of fat content. 


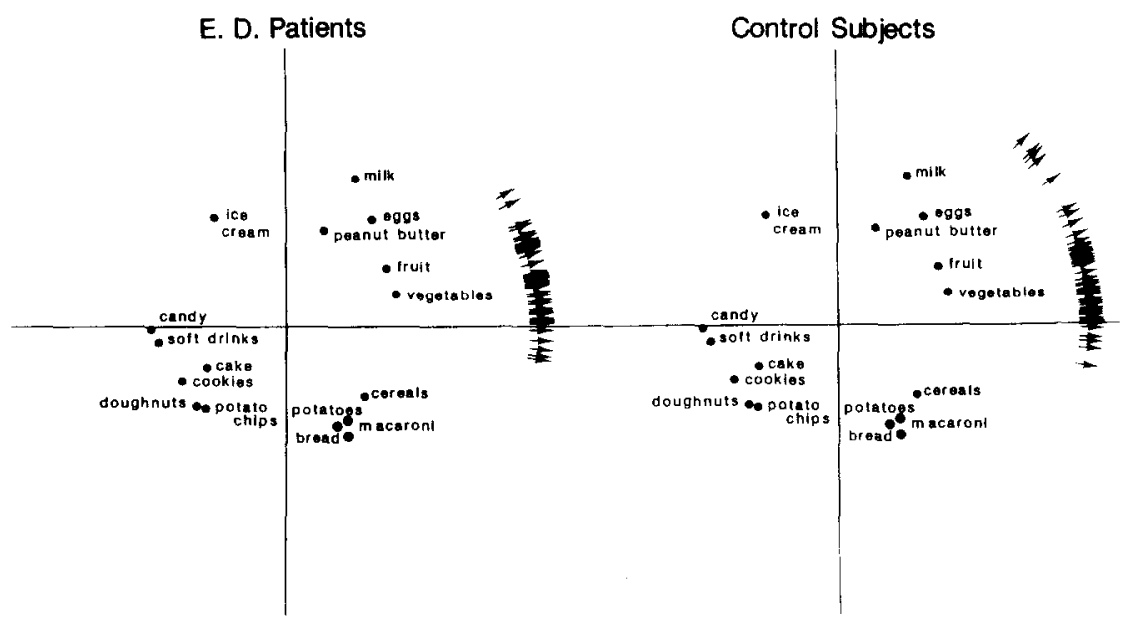

Figure 3. Plot of SINDSCAL stimulus space and individual attribute vectors reflecting nutritional value.

clustered in the top right-hand quadrant of the MDS solution (Figure 3). No significant difference was observed between eating disorder patients and controls.

\section{Property Fitting}

Mean multiple regression coefficients and regression weights (direction cosines) obtained by PROFIT are shown in Table 2, separately for eating disorder patients and controls. Multiple correlations between MDS dimensions and attribute scales were significant $(P<0 \cdot 01)$, indicating that the scales were well fitted by the co-ordinates of the MDS space. The nutritional value attribute had a high mean regression weight on Dimension I ( 0.90 for patients and 0.95 for controls), indicating that the angle between Dimension I and the direction of the associated scale was small. Similarly the mean regression weight on Dimension I for perceived calories was high $(-0.95$ for patients and -0.96 for controls), showing a strong negative relationship between perceived

\section{TABLE 2}

Mean multiple correlation coefficients and regression weights (direction cosines) of attribute vectors on dimensions of stimulus space

\begin{tabular}{|c|c|c|c|c|c|c|}
\hline \multirow[b]{3}{*}{ Attribute vector } & \multicolumn{3}{|c|}{ Eating disorder patients $(N=43)$} & \multicolumn{3}{|c|}{ Volunteer controls $(N=49)$} \\
\hline & \multirow[b]{2}{*}{ Multiple $R$} & \multicolumn{2}{|c|}{ Dimension } & \multirow[b]{2}{*}{ Multiple $R$} & \multicolumn{2}{|c|}{ Dimension } \\
\hline & & 1 & 2 & & 1 & 2 \\
\hline Protein & $0 \cdot 70$ & 0.76 & 0.49 & $0 \cdot 71$ & 0.68 & 0.56 \\
\hline Fat & 0.53 & -0.75 & $0 \cdot 20$ & 0.48 & -0.69 & 0.40 \\
\hline Carbohydrate & 0.58 & -0.24 & -0.62 & 0.62 & -0.08 & -0.66 \\
\hline Calories & $0 \cdot 70$ & -0.95 & $-0 \cdot 04$ & 0.75 & -0.96 & $-0 \cdot 09$ \\
\hline Nutrition value & 0.89 & $0 \cdot 90$ & $0 \cdot 17$ & 0.91 & 0.95 & 0.23 \\
\hline
\end{tabular}

Note: All multiple correlations are significant at $p<0-01$ level of better. 
nutrition and calories. Values of regression weights for attributed protein and fat contents along Dimension I also revealed a negative relationship between perceived nutrition and perceived fat content and a positive relationship between nutrition and protein. In contrast, mean regression weights of carbohydrate content on Dimension I were low, suggesting that nutrition and carbohydrates were not always negatively linked. PROFIT analysis further identified the vertical axis with perceived carbohydrate versus protein content as seen by the regression weights along Dimension II. No significant differences between patients and controls were observed on any of the attribute ratings.

Correlations between attribute vectors provide further information about how patients and controls organize their perceptual space. The present correlations of vector cosines along Dimension I only (the "nutrition" dimension) showed that eating disorder patients viewed as nutritious chiefly those foods that were also low in fat and low in calories. Vector correlations between attributes of nutritional value and calories $(r=-0.45 ; p<0.05)$, and nutritional value and fat content $(r=-0.27 ; p<0.05)$ were both negative. For control subjects, correlations between nutrition and calorie vectors $(r=-0.04)$ and nutrition and fat content $(r=-0.17)$, though also negative, were less pronounced and not significant.

These data suggest that eating disorder patients associated "junk" foods with calories and fat content to a greater degree than did controls. In contrast, no difference in attitudes towards carbohydrate foods was observed. The observed vector correlations between nutrition and carbohydrate content of foods were low, and not significantly different between patients $(r=0.08)$ and controls $(r=0.03)$.

\section{Preference Mapping}

Individual preference vectors superimposed on the common stimulus space are shown in Figure 4. Patients and controls differed significantly in the orientation of preference vector cosines along Dimension I (Mann-Whitney $U=772.5 ; p<0.05$ ). Most eating disorder patients reported liking only those foods that were also viewed as nutritious, and tended to dislike high-calorie, fat-containing foods to a greater extent

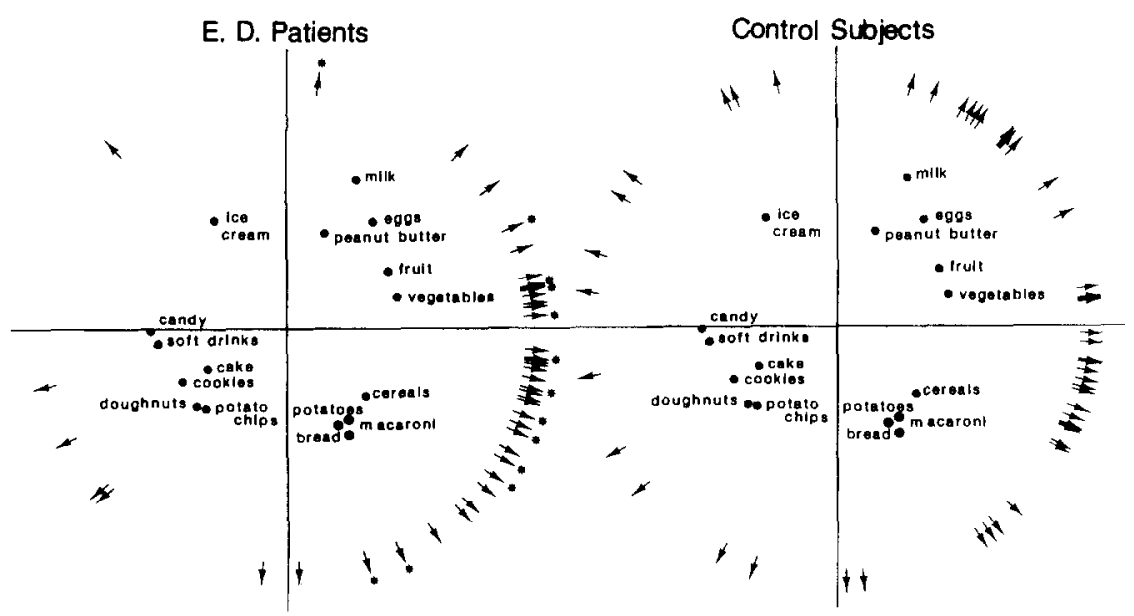

FIGURE 4. Plot of SINDSCAL stimulus space with individual preference vectors. Vectors representing anorectic restrictor patients are indicated by asterisks. 
than did controls. Consequently, their preference vectors showed high regression weights on Dimension I (mean $r=0.62$ ). This effect was most marked for $\Lambda$.N. restrictor patients (mean $r=0 \cdot 79$ ), whose vectors are indicated by asterisks. In contrast, normal controls and few of the bulimic patients admitted to preferences for some of the less nutritious foods. Their preference vectors showed lower regression weights on Dimension I (normal-weight bulimics: mean $r=0.48$; controls: mean $r=0.41$ ).

\section{Aspects of Preference}

The relationship between stated food preferences and perceived food attributes was examined further by correlating individuals' preference scores and attribute ratings. Mean correlation coefficients are summarized in Table 3. This analysis confirmed (following the analysis of vector cosines) that there were significant differences in preference structure between patients and controls. For eating disorder patients, food preferences and perceived calories were negatively linked (Table 3). For control subjects, the mean correlation coefficent between preference and calories was not as strong, and the difference in correlation coefficients between patients and controls was significant, $t(89)=2.40 p<0.05$. The patients also disliked high-fat foods to a greater extent than did controls. Correlations between preferences and fat content were negative and larger for patients than for controls (Table 3), $t(89)=3.46, p<0.01$. In contrast, food preferences were not linked to perceived carbohydrate content by either patients or controls, and there was no difference in the magnitude of the correlation coefficient between the two groups.

\section{Clustering Analysis}

The validity of an MDS solution is often confirmed using clustering analysis (Drewnowski, 1985). HICLUS analysis of the present data revealed the presence of five principal food clusters. The cluster of "fat/protein" foods included milk, eggs and peanut butter; "starches" included cereals, bread, macaroni and potatoes; "snacks" included ice cream, candy, potato chips and soft drinks, while "desserts" were doughnuts, cake and cookies. Fruit and vegetables formed a separate cluster. This structure closely corresponded to the perceptual map obtained from MDS, confirming the validity of the SINDSCAL solution. Analysis of mean attribute ratings confirmed that foods in the "fat/protein" cluster were indeed perceived as highest in fat and protein; that "starches" were viewed as highest in carbohydrate, and that "snacks" and

TABLE 3

Correlation coefficients between preference scores and food attribute ratings

\begin{tabular}{lcr}
\hline Altribute & $\begin{array}{c}\text { E.D. patients } \\
(N=42)\end{array}$ & $\begin{array}{c}\text { Control subjects } \\
(N=49)\end{array}$ \\
\hline Protein & $0 \cdot 10(0.05)$ & $0.11(0.04)$ \\
Fat & $-0.32(0.05)$ & $-0.06(0.05)$ \\
Carbohydrate & $-0.05(0.06)$ & $-0.02(0.04)$ \\
Calories & $-0.36(0.05)$ & $-0.21(0.04)$ \\
Nutrition value & $0.29(0.06)$ & $0.27(0.04)$ \\
\hline
\end{tabular}

Note: Data are means and $S E M$ (in parentheses). 
"desserts" were viewed as high in both carbohydrate and fat. There were no significant differences in nutritional assessment between eating disorder patients and controls.

For all subjects, mean preference ratings (Table 4) were highest for fruit and vegetables and for starchy foods. Eating disorder patients as a group showed much lower preferences for fat/protein foods, snacks and desserts than did the controls. Between-group comparisons ( $t$-tests) were significant at $p<0.005$ level or better. The patients' preferences for starches were below those of controls $(p<0 \cdot 05)$, although not as much as those for the other foods. Their preferences for vegetables and fruit were higher, but not significantly so.

These differences in food preference were largely due to the anorectic restrictor patients. These patients showed the most significantly reduced preferences for proteins/fats, snacks and desserts relative to controls $(p<0.001)$. However, even for this group thought to suffer from a "carbohydrate phobia", stated preferences for starches were reduced relatively little $(p<0.05)$ compared to those for high-fat, calorie-dense foods.

\section{DisCUSSION}

Ratings of the nutritional quality of foods did not differ between eating disorder patients and normal-weight control subjects. Patients and controls shared the same perceptual space, categorizing food names along dimensions of nutritional value, and carbohydrate content versus protein and fat. Measures of dimension salience (subject weights) were the same for both groups. Patients and controls did not differ in their assessments of the carbohydrate, fat and protein content of named common foods. Their perceptions of caloric density and nutritional value of foods were also similar.

Eating disorder patients nevertheless reported different patterns of food preference from those of control subjects. Preference vectors for patients with anorexia and bulimia (especially anorectic restrictors) were more closely linked to the nutritionrelated Dimension I. The patients expressed preferences chiefly for the nutritious and low-calorie foods. Correlational analyses further showed that their food preferences were negatively linked to the perceived fat and calorie content of foods. These negative correlations were significantly higher for eating disorder patients than for controls. In contrast, carbohydrate content was not linked to food preferences cither for paticnts or

TABLE 4

Mean preferences for the principal food clusters as a function of subject group

\begin{tabular}{|c|c|c|c|c|}
\hline & $\begin{array}{l}\text { AN-restrictor } \\
(N=13)\end{array}$ & $\begin{array}{l}\text { AN-bulimic } \\
\text { and bulimic } \\
\quad(N=29)\end{array}$ & $\begin{array}{c}\text { E.D. patients } \\
\text { total } \\
(N-42)\end{array}$ & $\begin{array}{l}\text { Controls } \\
(N=49)\end{array}$ \\
\hline Proteins/fats & $4.82(0.42)$ & $5.56(0.33)$ & $5 \cdot 33(0.26)$ & $6.62(0.20)$ \\
\hline Starches & $6.37(0.36)$ & $6.63(0-29)$ & $6.55(0.22)$ & $7 \cdot 15(0 \cdot 12)$ \\
\hline Snacks & $4.35(0.49)$ & $5.37(0.34)$ & $5.05(0.29)$ & $6 \cdot 20(0-18)$ \\
\hline Desserts & $4.49(0.17)$ & $5.75(0.45)$ & $5 \cdot 36(0.38)$ & $6.81(0.21)$ \\
\hline Fruits and vegetables & $8.12(0.25)$ & $8.14(0.13)$ & $8 \cdot 13(0 \cdot 12)$ & $7.80(0.18)$ \\
\hline
\end{tabular}


for controls. The notion of a specific "carbohydrate phobia" in eating disorders may well be a misnomer. The present attitudinal measures reveal that eating disorder patients predominantly disliked foods that were high in calories - that is, foods rich in fat.

As suggested by clinical reports, anorectic restrictor patients applied the most rigid rules to food preference measures, claiming to like only the most nutritious foods. The patients' stated preferences for proteins and fats, snacks and desserts were much lower than controls' preferences, with anorectic restrictor patients again expressing the most extreme views. However, even restrictors' preferences for carbohydrate-rich foods were only slightly lower than those of control subjects.

It is important to note that the present study measured attitudes rather than actual nutritional knowledge or overt eating behavior. The accuracy of nutritional information was not tested, and no attempt was made to determine whether patients in fact avoided the foods they claimed to dislike. The chief importance of this method lies in the accurate assessment of attitude structure. MDS techniques were used to map nutritional perceptions of eating disorder patients to explore links between food attitudes and beliefs and self-reported statements of food preference.

Studies on consumer preferences have generally distinguished between three components of attitude (1) cognitive--reflecting perceptions and evaluation of a given object; (2) affective - usually defined as feelings of like and dislike; and (3) behavioral best defined in terms of behavioral intentions (Fishbein \& Ajzen, 1975). It is well known that a change in one of the dimensions of attitude (cognitive, affective, or behavioral) sometimes leads to a change in others. This reportedly occurs because most individuals cannot tolerate an inconsistency between the cognitive and affective components of attitude (Rosenberg, 1965). Eating disorder patients, characterized by rigid attitude structure, might be especially prone to minimize inconsistencies in nutrition-related attitudes and behavior. Clinical reports indicate that anorectic patients apply the strictest rules to everything consumed, diet rigorously and permit themselves to eat only the healthiest, most nutritious, calorie-sparing foods (Garner et al., 1985). The chief rationale of cognitive therapy is that successful assimilation of new cognitive information during nutritional counseling will alleviate dichotomous thinking, alter food preferences and improve food choice.

The present study suggests that both patients and controls share the same perceptions of the nutritional value of common foods. The lack of nutritional information does not appear to be an issue. However, our results are wholly consistent with the view that some eating disorder patients (especially anorectic restrictors) show a rigid attitude structure that does not allow for cognitive dissonance. While their perceptions of nutritional value of food were not different from those of other groups, anorectic women did appear to apply stricter rules to preference judgments, allowing themselves to express preferences only for the most wholesome and nutritious foods.

In contrast, some bulimic patients (but no anorectics) reported a liking for nonnutritious "junk" foods. In a previous study (Drewnowski, 1985) obese patients have shown such a pattern, admitting to liking foods which they themselves viewed as unhealthy. The expressed liking of such foods was taken to indicate attitude-discrepant behavior, which may contribute to the feelings of guilt, shame, and helplessness often reported by the obese patient following eating binges. These findings are also consistent with the notion that attitude-discrepant behavior contributes to the "dietary chaos" syndrome in bulimia. The same cognitive mechanism may be partly responsible for the purging of "bad" foods following an eating binge. In contrast, anorectic restrictor 
patients appear to be characterized by rigid and perfectionistic attitudes, and a greater degree of self-control.

Finally, the present findings that anorectic women dislike not carbohydrate but fat appear to differ from those of previous investigators (e.g. Russell, 1967). However, this seeming discrepancy may be due in part to a secular trend. In the past, carbohydrate calories may have been avoided because of an overwhelming desire to lose weight. In other words "carbohydrate phobia" may be secondary to a "weight phobia" as previously proposed by Crisp and Kalucy (1974). At the time of Russell's studies, most weight-reducing diets available to the general public were high-protein, lowcarbohydrate formulations (Atkins, 1972; Stillman \& Baker, 1967). Carbohydrate was often viewed as uniquely fattening, while sugar was denounced as "pure, white and deadly" (Yudkin, 1972). By 1987, there has been a change in views: low-protein, low-fat, high-carbohydrate diets have been-endorsed both by health professionals (Raab \& Tillotson, 1983) and by the popular press (Eyton, 1983; Haas, 1983). The current emphasis in nutrition has been on fat as the single most concentrated source of calories. Diet-conscious anorectic women are clearly aware of such trends, and even psychopathology is not immune from societal influences and the mass media. Although the rejection of fat may have some physiological basis (Drewnowski et al., 1987), the greater aversion to fats than to carbohydrates by the eating disorder patients may also be influenced to some degree by changing trends in nutritional opinion.

\section{REFERENCES}

Abraham, S. F. \& Beumont, P. J. V. (1982) How patients describe bulimia or binge eating. Psychological Medicine, 12, 625-635.

American Psychiatric Association (1987) Diagnostic and statistical manual of mental disordersrevised (DSM IIIR). Washington, DC.: American Psychiatric Association.

Atkins, R. (1972) Dr. Atkins' diet revolution. New York: David McKay.

Beumont, P. J. V. \& Chambers, T. L. (1981) The diet composition and nutritional knowledge of patients with anorexia nervosa. Journal of Human Nutrition, 35, 265-273.

Casper, R. C., Eckert, E. D. \& Halmi, K. A. (1980) Bulimia: Its incidence and clinical importance in patients with anorexia nervosa. Archives of General Psychiatry, 37, 1030-1035.

Crisp, A. H. (1965) Some aspects of the evolution, presentation and follow-up of anorexia nervosa. Proceedings of the Royal Society 58, 814-820.

Crisp, A. H. \& Kalucy, R. S. (1974) Aspects of the perceptual disorder in anorexia nervosa. British Journal of Medical Psychology, 47, 349-361.

Drcwnowski, A. (1982) Cognitive structure in obesity and dieting. In: M. R. C. Greenwood (ed.), Obesity: Contemporary issues in clinical nutrition. Pp. 87-101. New York: ChurchillLivingstone.

Drewnowski, A. (1985) Food perceptions and preferences of obese adults: A multidimensional approach. International Journal of Obesity, 9, 201-212.

Drewnowski, A. (1987) Changes in mood after carbohydrate consumption. American Journal of Clinical Nutrition, 46, 703.

Drewnowski, A., Riskey, D. \& Desor, J. A. (1982) Feeling fat yet unconcerned: Self-reported overweight and the restraint scale. Appetite, 3, 273-279.

Drewnowski, A., Greenwood, M. R. C. \& Halmi, K. A. (1984) Carbohydrate or fat phobia: Taste responsiveness in anorexia nervosa. Federation Proceedings, 43, 475.

Drewnowski, A., Halmi, K. A., Pierce, B., Gibbs, J. \& Smith, G. P. (1987) Taste and eating disorders. American Journal of Clinical Nutrition, 46, 442-450.

Eyton, A. (1983) F-Plan diet. Ncw York: Bantam Books.

Fishbein, M. \& Ajzen, I. (1975) Attitude, belief, intention and behavior. Reading, MA: AddisonWesley. 
Garner, D. M. \& Bemis, K. M. (1980) A cognitive-behavioral approach to anorexia nervosa. Cognitive Therapy and Research, 6, 123-150.

Garner, D. M. \& Garfinkel, P. E. (1985) Cognitive therapy for anorexia nervosa. In: D. M. Garner \& P. E. Garfinkel (Eds), Handbook of psychotherapy for anorexia nervosa and bulimia. New York: Guilford Press.

Garner, D. M., Rockert, W., Olmstead, M. P., Johnson, C. \& Coscina, D. V. (1985) Psychoeducational principles in the treatment of bulimia and anorexia nervosa. In D. M. Garner \& P. E. Garfinkel (Eds), Handbook of psychotherapy for anorexia nervosa and bulimia. New York: Guilford Press.

Haas, R. (1983) Eat to win. New York: Rawson Associates.

Halmi, K. A., Falk, J. R. \& Schwartz, E. (1981) Binge-eating and vomiting: a survey of a college population. Psychological Medicine, 11, 697-706.

Hamill, P. V. V., Drizd, T. A., Johnson, C. L., Reed, R. B., Roche, A. F. \& Moore, W. M. (1974) Physical growth: National Center for Health Statistics percentiles. American Journal of Clinical Nutrition, 32, 607-629.

Herman, C. P. (1978) Restrained eating. Psychiatric Clinics of North America, 1, 593-607.

Hurst, P. S., Lacey, J. H. \& Crisp, A. H. (1977) Teeth, vomiting and diet: A study of the dental characteristics of seventeen anorexia nervosa patients. Postgraduate Medical Journal, 53 , 298-305.

Johnson. S. C. (1967) Hierarchical clustering schemes. Psychometrika, 32, 241-254.

Logue, A. W., Logue, K. R. \& Strauss, K. E. (1983) The acquisition of taste aversions in humans with eating and drinking disorders. Behavioral Research \& Therapy, 21, 275-289.

Mitchell, J. E. \& Laine, D. C. (1985) Monitored binge-eating behavior in patients with bulimia. International Journal of Eating Disorders, 4, 177-183.

Pennington, J. A. T. \& Church, H. N. (1980) Food values of portions commonly used. New York: Harper \& Row.

Peryam, D. R. \& Pilgrim, F. J. (1957) Hedonic scale method of measuring food preferences. Food Technology, 11, 9-14.

Raab, C. \& Tillotson, J. (Eds) (1983) Heart to heart: A manual for nutritional counseling for the reduction of cardiovascular disease risk factors. NIH Publication No. 83-1528. Bethesda. MD: U.S. DHHS.

Roering, K. J., Boush, D. M. \& Shipp, S. H.(1986) Factors that shape eating patterns: A consumer behavior perspective. In What is America eating? Washington, D.C.: Food and Nutrition Board Symposium, National Academy Press.

Rosen, J. C., Leitenberg, H., Fisher, C. \& Khazam, C. (1986) Binge eating episodes in bulimia nervosa: The amount and type of food consumed. International Journal of Eating Disorders, $5,255-267$.

Rosenberg, M. J. (1965) Inconsistency arousal and reduction in attitude change. In: Current studies in social psychology. Pp. 123-124. New York: Holt, Reinhart and Winston.

Russell, G. F. M. (1967) The nutritional disorder in anorexia nervosa. Journal of Psychosomatic Research, 11, 141-149.

Russell, G. F. M. (1979) Bulimia nervosa: an ominous variant of anorexia nervosa. Psychological Medicine, 9, 429-448.

Schiffman, S. S., Reynolds, M. L. \& Young, F. W.(1981) Introduction to multidimensional scaling: Theory, methods and applications. New York: Academic Press.

Shepherd, R. \& Stockley, L. (1985) Fat consumption and attitudes towards food with a high fat content. Human Nutrition: Applied Nutrition, 39 A, 431-442.

Stillman, I. M. \& Baker, S. S. (1967) The doctor's quick weight loss diet, Englewood Cliffs. NJ: Prentice-Hall.

Yudkin, J. (1972) Sweet and dangerous. New York: Bantam Books.

Received 9 June 1987, revision 8 December 1987 